\title{
IMPACTO DA FACILITAÇÃO DE COMÉRCIO NO MERCOSUL EM COMPARAÇÃO À UNIÃO EUROPEIA: UMA ANÁLISE ATRAVÉS DO MODELO GRAVITACIONAL
}

\author{
Nome \\ Igor de Menezes Larruscaim \\ Instituição/Afiliação \\ Mestrando do Programa de Pós-Graduação em Economia e Desenvolvimento da \\ Universidade Federal de Santa Maria (UFSM). E-mail: \\ igor_menezes06@hotmail.com \\ País \\ Brasil \\ Nome \\ DANIEL ARRUDA CORONEL \\ Instituição/Afiliação \\ Professor do Programa de Pós-Graduação em Economia e Desenvolvimento da \\ Universidade Federal de Santa Maria (UFSM) e Bolsista de Produtividade do CNPq. \\ E-mail: daniel.coronel@uol.com.br \\ País \\ Brasil \\ Nome \\ Paulo Ricardo Feistel \\ Instituição/Afiliação \\ Professor do Programa de Pós-Graduação em Economia e Desenvolvimento da \\ Universidade Federal de Santa Maria (UFSM). E-mail: prfeistel@gmail.com \\ País \\ Brasil \\ Nome \\ Clailton Ataides de Freitas \\ Instituição/Afiliação \\ Professor do Programa de Pós-Graduação em Economia e Desenvolvimento da \\ Universidade Federal de Santa Maria (UFSM). E-mail: caf@ccsh.ufsm.br \\ País \\ Brasil
}

\section{RESUMO}

Este estudo tem como objetivo analisar o grau de facilitação do comércio e sua relação com o padrão de comércio dos países do Mercado Comum do Sul (Mercosul) em relação aos países da União Europeia. A facilitação do comércio envolve fatores como características do ambiente institucional interno, nível de burocracia existente no comércio internacional, que podem implicar em redução dos custos dessas transações. O procedimento metodológico envolveu o uso de estatística multivariada para a construção de índices de facilitação do comércio através da análise fatorial e o uso da estimação em dados em painel através do modelo gravitacional para analisar o impacto desses índices sobre o comércio bilateral dos blocos. Os resultados indicaram impacto positivo da melhoria desses índices sobre o fluxo de comércio dos países, melhorias nos procedimentos alfandegários e processos burocráticos internos.

Palavras-chave: Facilitação de comércio, Mercosul, União Europeia

\begin{abstract}
The present study aims to analyze the degree of trade facilitation and its relation with the trade standard of the countries from Southern Common Market - Mercosur (Mercado Comum do Sul Mercosul) in relation to the European Union countries. The trade facilitation involves all set of factors, such as the characteristics of the internal institutional environment and level of existent bureaucracy for the performance of international trade and that can imply in reduction of these transaction costs. The methodological procedure involved the use of multivariate statist ic for the construction of trade facilitation indexes through the factorial analysis and the use of estimation in panel data through the
\end{abstract}


gravitational model to analyze the impact of these indexes on the bilateral trade of blocks. The results indicated positive impact of these indexes improvement on the trade flow of the countries.

Key-words: Trade Facilitation, Mercosur, Europe Union

Classificação JEL: F13; F15.

\section{INTRODUÇÃO}

A forma com que os países se inserem no comércio internacional difere de maneira significativa entre determinadas nações. Ainda que a relação positiva entre crescimento e fluxo de comércio internacional esteja estabelecida na teoria, o exercício empírico envolve alguns desafios em estabelecer métodos que evidenciem essa diferença no desempenho competitivo dos países no comércio internacional e como essa relação com o crescimento é estabelecida. Algumas questões devem ser analisadas então para se definir quais os elementos que influem diretamente sobre a competitividade e o nível de comércio dos países.

A liberalização comercial e o aumento do comércio internacional passam, além da liberalização tarifária, pelas barreiras não tarifárias, que envolvem as características do ambiente institucional interno e nível de burocracia existente para a realização de exportações e importações. A facilitação do comércio envolve esse conjunto de fatores que implicam custos de comercialização internacional reduzidos. Houve um amplo esforço recente no cenário político internacional em prol da liberalização comercial e redução de tais barreiras. A importância da facilitação comercial tem destaque como pauta de discussão na Organização Mundial do Comércio (OMC), na conferência Ministerial de Cingapura, em 1996, e foi reforçada como tema na agenda de discussões na Rodada de Doha, em 2003 (SOUZA; BURNQUIST, 2011; SANT’ANNA; SOUZA, 2014).

O entendimento de facilitação do comércio pode ter mais de um sentido e englobar diversas variáveis, por isso implica interpretações distintas. Desta forma, o conceito considerado neste estudo é o entendimento de facilitação do comércio presente na literatura empírica sobre o tema (SOUZA; BURNQUIST, 2011, 2012; SANT’ANNA; SOUZA, 2014; SADIKOV, 2007; WILSON; MANN e OTSUKI, 2004). Esses autores consideram facilitação do comércio como um conjunto de políticas que reduzem os custos de comercialização internacional, o que envolve os chamados borders elements (elementos de fronteira), que se referem à eficiência das atividades portuárias e alfandegárias. Também incluem os elementos chamados inside the border (dentro da fronteira), que representam o ambiente institucional e envolvem regulação, legislação, transparência e infraestrutura. 
Dentro desse esforço de ampliação do comércio internacional em anos recentes, houve uma expansão do número de acordos de livre comércio, passando de 25 até 1990 para 158 no período 2001/2012, segundo dados da OMC. A "nova onda de acordos comerciais", consequentemente, traz reflexos sobre o desempenho comercial brasileiro, principalmente, as iniciativas do Acordo de Associação Transpacífico (TPP), o Acordo Transatlântico e a Aliança do Pacífico. Junto a este cenário, o bloco econômico do Mercado Comum do Sul (Mercosul) se mostrou frágil como união aduaneira, o que leva a uma discussão sobre a agenda de acordos comerciais do Brasil, visto que, dado tal cenário, poderia representar uma perda de acesso a outros mercados e um isolamento de cadeias produtivas globais para o país (PEREIRA, 2013).

A criação do Mercosul em 1991 representou um compromisso dos países fundadores, Brasil, Argentina, Paraguai e Uruguai em constituir um dos principais Acordos Preferências de Comércio (APC's) da América Latina. Entre as implicações presentes no tratado de constituição do bloco estavam a livre circulação de bens, serviços e fatores de produção além de coordenação nas políticas de comércio exterior entre os países membros (MERCOSUL, 1991). Esse é um dos principais acordos comerciais em que o Brasil e os demais países membros estão envolvidos e representaria uma forma de facilitação do comércio para eles. No contexto do cenário atual dos acordos comerciais e do próprio bloco, visto que a adesão de APC's se constitui como uma forma de liberalização comercial, mesmo que regionalmente, o que pode ser identificado como uma forma de facilitação ao comércio, uma das questões a serem respondidas é de que forma os países membros do Mercosul estabelecem suas políticas de facilitação do comércio em relação aos seus parceiros de bloco e demais parceiros comerciais?

Desta forma, o presente estudo tem como objetivo analisar o grau de facilitação do comércio e sua relação com o padrão de comércio dos países do Mercosul em relação aos países da União Europeia. A escolha da União Europeia para a análise do comércio bilateral se deve ao fato deste bloco ter preferência nas relações comerciais do Mercosul (VALLE, 2005). Para que o objetivo proposto seja alcançado, será utilizada a análise fatorial para a construção de índices que visam mensurar a facilitação de comércio, baseado na metodologia aplicada em SOUZA; BURNQUIST, 2011; SOUZA; FARIA E SANT'ANNA, 2012. Para analisar a relação entre os índices e o comércio bilateral, foi utilizado o modelo gravitacional, através da utilização de dados em painel, para o período de 2010-2016. 
O estudo busca atualizar o debate sobre facilitação do comércio e definir como essa relação se estabelece entre dois blocos econômicos distintos. Tal proposta de pesquisa se justifica pela possível contribuição que os resultados a serem obtidos podem oferecer, descrevendo o quanto as relações de comércio podem afetar no desempenho econômico dos países do bloco do Mercosul e em que medida essa forma de integração impacta sobre os países membros e as suas políticas de facilitação de comércio poderiam ser alteradas.

Este trabalho está estruturado em quatro seções, além desta introdução. Na segunda seção, apresenta-se a revisão bibliográfica; na seção seguinte, os procedimentos metodológicos são esboçados; na quarta seção, os resultados são analisados e discutidos e, por fim, apresentam-se as conclusões do trabalho.

\section{REVISÃO DA LITERATURA}

Nesta seção, é realizada a revisão sobre os estudos que buscam discutir e analisar empiricamente os efeitos de criação do Mercosul, bem como os estudos que avaliam os impactos da facilitação do comércio.

\subsection{Mercosul: surgimento e efeitos}

O surgimento do Mercosul ocorreu em um novo período de crescimento dos acordos de preferência comercial (APC's). A formação do bloco previa a livre circulação de produtos, serviços, trabalhadores e capital e coordenação nas políticas comerciais e macroeconômicas entre os países membros. O acordo reúne um grupo de países com dimensões bastante díspares e ocorreu como uma decisão política de aproximar países que compartilham fronteira. Outro aspecto é o fato de os países membros estarem passando por um processo de reestruturação política e redemocratização, o que demonstra mudanças em perspectivas políticas desses países, visto que internamente os países também buscaram uma ampliação do processo de liberalização econômica desde a metade dos anos 1980 até parte dos anos 1990 (AZEVEDO, 2004; BAUMANN, 2011).

Sobre o Mercosul, Azevedo (2004) buscou avaliar os efeitos da criação do bloco sobre o padrão de comércio dos países membros, utilizando a metodologia do modelo gravitacional e as seguintes variáveis para determinação do modelo: o PIB; distância absoluta; distância 
absoluta; taxa de câmbio; área; variável dummy para adjacência; dummy no caso de ilha; dummy para o idioma e dummy para o APC a qual pertence, incluindo outros blocos além do Mercosul para controle. Os resultados obtidos demonstram que, apesar do aumento do comércio intrabloco após a assinatura do tratado, em 1991, esse crescimento não é causado pela formação do bloco. O modelo demonstrou que, no período anterior à formação, já ocorria um viés regional no comércio entre esses países. Quanto ao comércio para fora do bloco, os resultados indicam que, devido à constituição do bloco, os países membros apresentaram um aumento de importações de países fora do bloco e uma redução de suas exportações extrabloco, o que pode indicar um "desvio de exportação".

O trabalho de Reis e Azevedo (2008) também visou identificar se a formação do bloco causou efeitos sobre o padrão de comércio dos países membros. Neste estudo, além da utilização do modelo gravitacional que avaliou o período pré-bloco entre 1987-1990 e o período de união aduaneira incompleta entre 1995-1998, os autores utilizaram uma metodologia de análise conjunta do Índice de Orientação Regional (IOR) e o Índice de Vantagem Comparativa Revelada (IVCR) no período de 1997-2001. O estudo identificou que, dentro do período 1997-2001, ocorreu um crescimento do comércio intrabloco, mas esse crescimento manifestou-se em produtos em que os países membros eram pouco competitivos mundialmente, o que pode indicar que a criação do bloco gerou um desvio de comércio ao invés de estimular o comércio entre seus membros propriamente. Os resultados obtidos através do modelo gravitacional também indicaram que o crescimento do comércio entre os países membros ocorreria mesmo sem a criação do bloco.

Gräf e Azevedo (2012) buscaram estimar o fluxo potencial de comércio dos países membros do Mercosul a partir do modelo gravitacional com análise em dados em painel. Para o ano de 2009, os resultados do modelo de efeitos fixos demonstravam um excedente no fluxo real de comércio em comparação ao fluxo potencial estimado pelo modelo para todas as relações de comércio bilateral entre os países membros do bloco, com exceção do fluxo bilateral Uruguai x Argentina, onde haveria algum potencial de comércio a ser explorado. Para a estimação do modelo de efeitos aleatórios para o ano 2009 também, alguns dos resultados apresentaram um potencial de comércio a ser explorado ainda. Para cada par de países do bloco, o fluxo com maior potencial de comércio estimado acima do comércio real é o fluxo Argentina x Uruguai. Já no caso do Brasil, o comércio real excede o fluxo potencial em todos os fluxos onde é exportador, para as importações apenas na relação Paraguai $\mathrm{x}$ Brasil ainda existe algum potencial de comércio. Isso pode indicar que o país está exercendo 
um grau de abertura maior em relação aos parceiros membros do bloco em detrimento ao comércio com demais países.

Considerando a criação do Mercosul como um esforço dos países membros em facilitar e, consequentemente, ampliar as relações de comércio internamente ao bloco e com demais blocos e países parceiros comerciais, é preciso definir o que se entende por esse processo de facilitação de comércio. Esse conjunto de procedimentos, que vai além da redução de barreiras tarifárias, é tratado no próximo tópico.

\subsection{Facilitação de comércio: conceito e estudos empíricos}

A facilitação de comércio, considerando o conjunto de fatores que o caracterizam, mostra-se crucial para a redução dos custos de comércio entre países. Este é um fator que se torna ainda mais relevante para a integração econômica dos países em uma economia global em processo de crescimento, e este é um desafio que surge, principalmente após a crise financeira global no final da década passada. Ainda que não haja uma definição teórica precisa, há uma ampla gama de modelos teóricos, mesmo com pressupostos distintos, que apresentam resultados econômicos positivos com a facilitação do comércio proporcionando redução dos seus custos. Nesse sentido, os custos de comércio representariam o mesmo efeito da aplicação de uma taxa ad valorem que teria um efeito de quase o dobro para os países em desenvolvimento do que os países de alta renda enfrentariam. A expansão da facilitação de comércio pode representar um incremento ao comércio de produtos agrícolas perecíveis, assim como também beneficiar o comércio de bens manufaturados intermediários (WORLD TRADE ORGANIZATION, 2015).

No que tange às políticas ou procedimento de facilitação de comércio, há diversos estudos que avaliaram esses aspectos para blocos econômicos e países. Wilson, Man e Otsuki (2003) buscaram analisar o processo de facilitação do comércio aos países membros da Asia Pacific Economic Cooperation (APEC) para o período entre 1989-2000. Para tanto, os autores constroem índices de facilitação do comércio utilizando análise fatorial, que estariam classificados em quatro categorias: eficiência portuária; ambiente alfandegário; ambiente regulatório e uso de E-bussines, que mede a infraestrutura doméstica como telecomunicações, intermediários financeiros, empresas de logística, etc. Para estabelecer a relação entre a facilitação do comércio e os fluxos comerciais dos países do bloco, os autores utilizam o modelo gravitacional. Os resultados obtidos a partir da estimação do modelo indicaram que, 
quanto melhor é o desempenho das variáveis designadas para medir a facilitação do comércio, maior a tendência de ampliação do fluxo comercial dos países, tanto intrabloco como para fora deste.

Souza e Burnquist (2011) analisaram os efeitos dos procedimentos de facilitação do comércio para um conjunto de países a partir do modelo gravitacional. Os autores também utilizaram a construção de índices de facilitação comercial a partir da análise fatorial que são relacionados com os dados sobre comércio bilateral entre países. Os autores constatam que, de modo geral, existe uma relação positiva entre os índices de facilitação e o incremento do comércio bilateral entre países devido à redução dos custos de comércio que resultam dessa facilitação. O estudo ainda indicou que os benefícios resultantes da facilitação podem variar de acordo com o produto que é comercializado. Os impactos sobre produtos com maior grau de processamento são maiores em relação a matérias-primas. Outra constatação é que os ganhos são potencializados quando um maior número de países proporciona uma melhoria nesses processos.

Paula, Da Silva e Almeida (2012) seguem na mesma linha e buscam identificar, além dos aspectos de facilitação do comércio, indicadores de competividade internos e de fronteiras através do modelo gravitacional para uma amostra de 57 países no período de 1997-2010. Os indicadores de competitividade são desempenho econômico; eficiência do governo; eficiência dos negócios e infraestrutura. Esses indicadores foram retirados do IMD World Competitiveness Yearbook 2011, são determinados de acordo com diversos critérios e estão relacionados com as variáveis tradicionais do modelo gravitacional. Os resultados obtidos estão dentro do que era esperado e indicam um efeito positivo sobre os fluxos de comércio bilateral com a melhoria desses indicadores. Um dos indicadores com maior magnitude foi o de infraestrutura, o que indica que, além do desempenho econômico, procedimentos alfandegários e burocráticos de forma geral, uma boa infraestrutura pode garantir o aproveitamento de oportunidades de comércio internacional para os países.

Sant'Ana e Souza (2014) analisaram o impacto da facilitação do comércio para as exportações brasileiras. O estudo utilizou o modelo gravitacional para estabelecer uma relação entre as exportações brasileiras e os índices de facilitação do comércio construídos através de análise fatorial a partir dos nove pilares de facilitação do comércio estabelecidos em The Global Enabling Trade Report (2010) do Fórum Econômico Mundial para o período 20082010. São criados dois índices: o primeiro busca agregar as informações de todos os pilares para definir um índice único de facilitação do comércio e o segundo é o Índice de 
Heterogeneidade de Facilitação de comércio - IHF, que evidencia o nível de semelhança e diferença entre o Brasil e os seus parceiros comerciais quanto à facilitação do comércio. Os resultados alcançados indicaram que o padrão de facilitação do comércio do país influencia positivamente o fluxo de comércio do país. O estudo indicou que o país poderia realizar reformas que possibilitem uma maior facilitação do comércio e, consequentemente, redução dos custos de comércio, elevando a competitividade do país no cenário internacional. Essas melhorias também contribuiriam para o Brasil diminuir a heterogeneidade de facilitação em relação aos países com melhores índices de facilitação, o que representaria ganhos significativos ao comércio do país.

\section{METODOLOGIA}

O procedimento metodológico envolve a utilização de estatística multivariada para a construção de índices de facilitação do comércio através da análise fatorial. Os índices buscaram evidenciar qual o grau de relevância dos procedimentos, tempo e custos envolvidos para importações e exportações no sentido dos conceitos on the border (elementos de fronteira) e behind the border (elementos dentro da fronteira) como definido em Sadikov (2007). A criação de índices de facilitação do comércio a partir do método de análise fatorial também é empregada em Faria e Burnquist (2006), Souza e Burnquist (2008), Souza e Burnquist (2012) e Sant'Anna e Souza (2014). Os índices obtidos são inseridos na função de regressão do modelo gravitacional, com as variáveis tradicionais do Produto Interno Bruto (PIB) e a distância entre os países que realizam o comércio bilateral. A intenção é verificar o impacto da facilitação do comércio sobre esses fluxos comerciais.

\subsection{Construção dos índices através de análise fatorial}

O método de estatística multivariada de análise fatorial permite a redução do número $m$ original de variáveis aleatórias através da obtenção de fatores comuns que se relacionam com o vetor original $X$ em um modelo linear. Isso implica que as vaiáveis originais $X_{i}, i=$ $1,2, \ldots, p$ sejam agrupadas em subconjuntos de novas variáveis, os fatores comuns, que não se correlacionam entre si. As novas variáveis obtidas a partir das variáveis originais podem sumarizar informações dos vetores originais, ou seja, os fatores ou variáveis latentes. Com a obtenção dos fatores, é possível a elaboração de índices que evidenciem as diferenças nas informações das variáveis originais (MINGOTI, 2005). 
De acordo com Mingoti (2005, p.101), “o modelo de análise fatorial construído a partir da matriz de correlação teórica $P_{p x p}$ é um modelo que relaciona linearmente as variáveis padronizadas e os $\mathrm{m}$ fatores comuns, que a princípio, são desconhecidos”. As variáveis padronizadas são dados por $Z_{i}=\left[\left(X_{i}-\mu_{i}\right) / \sigma_{i}\right]$, o vetor $X_{i}$ é um vetor aleatório, $\mu_{i}$ é a média desse vetor e $\sigma_{i}$ o seu desvio-padrão. As equações do modelo são dadas por:

$$
\begin{aligned}
& Z_{1}=l_{11} F_{1}+l_{12} F_{2}+\ldots+l_{l m} F_{m}+\varepsilon_{1} \\
& Z_{2}=l_{21} F_{1}+l_{22} F_{2}+\ldots+l_{l m} F_{m}+\varepsilon_{2} \\
& \vdots \quad \vdots \quad \vdots \quad \vdots \quad \vdots \\
& Z_{p}=l_{p 1} F_{1}+l_{p 2} F_{2}+\ldots+l_{l m} F_{m}+\varepsilon_{p}
\end{aligned}
$$

sendo que $Z_{i}$ são as variáveis padronizadas, $F_{m x l}$ é o que se denomina como fator, que corresponde a um vetor aleatório que possui $\mathrm{m}$ fatores, que extraem elementos do conjunto de variáveis originais que não podem ser observados em princípio. O vetor $\varepsilon_{p x l}$ é o vetor de erros aleatórios e representa a variação de $Z_{i}$ que não pode ser explicado por $F_{j}, \mathrm{j}=1,2, \ldots, \mathrm{m}$. $\mathrm{O}$ coeficiente $l_{i j}$ é a carga fatorial, que é o coeficiente da $i$-ésima variável $Z_{i}$, no j-ésimo fator $F j$ e “representa o grau de relacionamento linear" entre esses dois vetores. Os coeficientes $l_{i j}$ são parte de uma matriz de parâmetros constantes $L_{p x m}$ (MINGOTI, 2005).

Os vetores $F$ e $\varepsilon$ correspondem a duas fontes de variação distintas em relação a $Z_{i}$. Como este é um modelo ortogonal, a matriz $P_{p x p}$ pode ser reparametrizada da seguinte maneira:

$$
P_{p x p}=L L^{y}+\Psi
$$

Isso implica que:

$\operatorname{Var}\left(Z_{i}\right)=l_{i 1}^{2}+l_{i 2}^{2}+\ldots+l_{i m}^{2}+\Psi_{i}=h_{i}^{2}+\Psi_{i}$, onde $h_{i}^{2}=l_{i 1}^{2}+l_{i 2}^{2}+\ldots+l_{i m}^{2}, i=1,2$ $\ldots, p$.

a variação de $Z_{i}$ é explicada em duas partes, $h_{i}^{2}$ é a variabilidade correspondente aos m fatores do modelo, e é chamada de "comunalidade", $\Psi_{i}$ é a variabilidade que corresponde ao erro aleatório do modelo, e é chamada de "variância específica". Como $\operatorname{Var}\left(Z_{i}\right)=1, \operatorname{logo}$ $h_{i}^{2}+\Psi_{i}=1$. A matriz de covariância fica da seguinte forma: 


$$
\begin{aligned}
& \operatorname{Cov}\left(Z_{i}, Z_{k}\right)=l_{i 1} l_{k 1}+l_{i 2} l_{k 2}+\ldots+l_{i m} l_{k m}, \quad i, k,=1,2, \ldots, p, i \neq k \\
& \operatorname{Cov}(Z, F)=L_{p x m}, \log 0 \operatorname{Cov}(Z, F)=\operatorname{Corr}\left(Z_{i}, F_{j}\right)=l_{i j}, i=1,2, \ldots, p ; j=1,2, \ldots, m_{;}
\end{aligned}
$$

isso permite que a matriz $L_{p x m}$ seja utilizada para a interpretação dos fatores $F j, j=1,2, \ldots, m$ (MINGOTI, 2005).

Para realizar a estimação da matriz $L_{p x m}$, é utilizado o método de componentes principais e o critério Varimax para a rotação ortogonal dos fatores, sendo um dos métodos comumente utilizados. Para a validação do modelo de análise fatorial, é utilizado o critério de Kaiser-Meyer-Olkin (KMO) e o teste de esfericidade de Bartlett. Os dados utilizados para a construção dos índices de facilitação de comércio foram retirados do site doing bussines do Banco Mundial. A variáveis estão relacionadas com a categoria já estabelecida nas bases de dados sobre Registro de propriedades, Comércio Internacional e Execução de contratos e são as seguintes:

\begin{tabular}{|c|c|c|c|}
\hline Nome & Variável & Dimensão & Fonte \\
\hline $\begin{array}{l}\text { Registro de propriedades }- \text { Número de } \\
\text { procedimentos }\end{array}$ & rp-npr & $\begin{array}{l}\text { Valor } \\
\text { Absoluto }\end{array}$ & Doing Bussines \\
\hline Registro de propriedades - Duração & rpd & Dias & Doing Bussines \\
\hline Número de documentos para importar (exportar) & ndoc & $\begin{array}{l}\text { Valor } \\
\text { absoluto }\end{array}$ & Doing Bussines \\
\hline Custo para importar & custo & $\begin{array}{l}\text { US\$ por } \\
\text { container }\end{array}$ & Doing Bussines \\
\hline Tempo para importar (exportar) & tempo & Dias & Doing Bussines \\
\hline $\begin{array}{l}\text { Tempo para importar (exportar): Conformidade } \\
\text { com a documentação }\end{array}$ & tdoc & Horas & Doing Bussines \\
\hline $\begin{array}{l}\text { Tempo para importar (exportar): Conformidade } \\
\text { com obrigações na fronteira }\end{array}$ & tfront & Horas & Doing Bussines \\
\hline $\begin{array}{l}\text { Custo para importar (exportar): Conformidade } \\
\text { com a documentação }\end{array}$ & cdoc & US\$ & Doing Bussines \\
\hline $\begin{array}{l}\text { Custo para importar (exportar): Conformidade } \\
\text { com obrigações na fronteira }\end{array}$ & cfront & US\$ & Doing Bussines \\
\hline
\end{tabular}

Tabela 1- Variáveis utilizadas para construção dos índices de facilitação de comércio 
Execução de contratos - Número de procedimentos $\begin{array}{ll}\text { Valor } & \text { Doing Bussines } \\ \text { absoluto } & \end{array}$

Execução de contratos - Duração

c-dur Dias

Doing Bussines

Execução de contratos - Custo

c-cust US\$

Doing Bussines

Fonte: Elaboração própria.

Com a obtenção dos fatores, espera-se reduzir a dimensão das variáveis originais e construir os índices com a agregação das variáveis com maior correlação com cada fator. Como não há disponibilidade de todos os dados para alguns países e para determinados anos do período 2010-2016, foram utilizadas as médias do período, , deste modo os índices são uma representação para todo o período de análise. Além disso, como ressaltam Souza e Burnquist (2012), a redução da dimensão das variáveis através da análise fatorial facilita a estimação econométrica, pois diminui os problemas de uma possível autocorrelação entre algumas dessas variáveis.

\subsection{Modelo gravitacional}

O uso do modelo gravitacional como forma de análise empírica em estudos sobre comércio internacional foi desenvolvido incialmente por Jan Tinbergen (1962) e Pöyhönen (1963) e atualmente é uma ferramenta amplamente utilizada para explicar as relações que envolvem o comércio bilateral. O modelo utiliza uma analogia com a lei da gravidade newtoniana em que, quanto maior a renda e menor a distância entre países, maior a tendência de que o comércio bilateral seja maior entre esses, assim como a força de atração de dois corpos é proporcional a sua massa e é maior à medida que a distância entre esses é menor (MAN; OTSUKI; WILSON，2003，SANTOS SILVA; TENREYRO，2006，SOUZA; BURNQUIST, 2012).

O trabalho de Anderson (1979) foi pioneiro em construir a fundamentação microeconômica para o modelo gravitacional. A extensão proposta em Anderson e Van Wincop (2003) é uma derivação do modelo gravitacional baseado em elasticidades de substituição constantes (CES) e considera que todos os bens são diferenciados de acordo com o local de origem e cada região é especializada em um bem. A maximização da função de utilidade com relação a CES é sujeita a uma restrição orçamentária. O modelo inclui também a consideração da "resistência multilateral" a qual indica que os custos do comércio não dependem apenas das barreiras bilaterais, mas envolvem também os custos dos demais 
parceiros comerciais que não estão envolvidos diretamente. A equação gravitacional é dada por:

$$
x_{i j}=\frac{y_{i} y_{j}}{y^{W}}\left(\frac{t_{i j}}{p_{i} P_{j}}\right)^{1-\sigma}
$$

Onde $x_{i j}$ é o fluxo de comércio bilateral entre a região $i$ e a região $j$; $y_{i}$ é o PIB do país $i$ e $y_{i}$ o PIB do país $j ; y^{W}$ é o produto agregado mundial; $t_{i j}$ são os custos envolvidos no comércio entre $i$ e $j$, quando $t_{i j}=1$ não há custos para se comercializar; $P_{i}$ e $P_{j}$ são, respectivamente, índices de preços das regiões $i$ e $j$, que representam as resistências multilaterais e $\sigma$ é a elasticidade de substituição entre todos bens (ANDERSON; WINCOOP, 2003).

As contribuições teóricas presentes em Anderson e Wincop (2003) consolidaram o modelo gravitacional como uma das ferramentas mais utilizadas em estudos empíricos sobre comércio bilateral. As variações decorrentes desse modelo passaram a incorporar ao modelo logarítmico tradicional, com as variáveis usuais do PIB e distância entre países, diversos outros elementos como impacto de tarifas, mobilidade dos fatores, custos de transporte, etc. Além da possibilidade de considerar os custos de comércio multilateral, o modelo permite uma vasta possibilidade de aplicações quanto ao comércio internacional e por isso se mostra um método bastante útil para a análise empírica (SHEPERD; WILSON 2008; PAULA; SILVA; ALMEIDA, 2012; ALMEIDA; GOMES; SILVA, 2014).

\subsection{Aplicação do modelo gravitacional}

Considerando a ampla possibilidade de aplicações do modelo gravitacional para a análise dos fenômenos econômicos envolvidos no comércio internacional, esse se mostra um método adequado para o objetivo proposto no trabalho, que é descrever o grau de facilitação de comércio que os países do Mercosul apresentam comparativamente ao bloco da União Europeia. Desta forma, são realizadas duas estimações, sendo uma para os fluxos comerciais de cada bloco econômico.

Grande parte da literatura utilizada recomenda a utilização do método de efeitos fixos na aplicação econométrica do modelo de Anderson e Van Wincoop (2003) na análise em painel. Os efeitos fixos se adaptam melhor quanto à heterogeneidade dos países na amostra $\mathrm{e}$ 
aos efeitos que são difíceis de captar, como a resistência multilateral (ANDERSON; VAN WINCOOP, 2003; SOUZA, BURNQUIST, 2011, 2012). No entanto, é realizado o teste de Hausman e de Chow para verificar se o modelo se adapta melhor ao método de efeitos fixos, aleatórios ou regressão pooled. Considerando o modelo de efeitos fixos, de acordo com Greene (2002), existindo um termo $z_{i}$, não observado, mas correlacionado com $x_{i t}$,ele é captado por um termo $\alpha_{i}$, onde o termo $\alpha_{i t}=z_{i t}^{\prime} \alpha$ engloba os efeitos observáveis do grupo na amostra, sendo um termo constante desse grupo no modelo.

Além do modelo de efeitos fixos, foram estimadas regressões em painel pooled e de efeitos aleatórios e também o modelo Poisson Pseudo-Maximum-Likelihood ${ }^{1}$ com efeitos fixos. Esse modelo é estimado utilizando efeitos fixos e fornece estimações mais robustas e é utilizado principalmente pela presença de valores zero na variável dependente e na presença de heteroscedasticidade (SANTOS SILVA; TENREYRO, 2006).

Desta forma, considerando todas as demais variáveis no modelo gravitacional padrão, com a equação na forma log-log, o modelo de regressão em painel proposto no estudo é formalmente:

$$
\begin{aligned}
\ln \left(M_{i j t}\right)=\alpha_{i j} & +\gamma_{t}+\beta_{1} \ln \left(Y_{i t}\right)+\beta_{2} \ln \left(Y_{j t}\right)+\beta_{3} \ln \left(D_{i j}\right)+\beta_{4} \ln \left(1+\tau_{i j t}\right)+\sum_{m} \beta_{m} \ln \left(I F C_{i}\right) \\
& +\sum_{n} \beta_{n} \ln \left(I F C_{j}\right)+\beta_{7} M s u l_{i j}+\beta_{8} M U E_{i j}+\beta_{9} M m u n d o_{i j}+\beta_{10} U E M_{i j}+\beta_{11} U E_{i j} \\
& +\varepsilon_{i j t}
\end{aligned}
$$

Onde: $M_{i j t}$ representa as importações do país $i$ para o país $j$ no ano $t ; \alpha_{i j}$ corresponde aos efeitos fixos constantes para cada par de países; $\gamma_{t}$ são as variáveis binarias correspondentes a cada ano da amostra ; $Y_{i t}$ e $Y_{j t}$ são respectivamente o PIB do país $i$ e do país $j$ no tempo $t ; D_{i j}$ é a distância entre os países $i$ e $j$; $\tau_{i j t}$ é a tarifa imposta pelo país $j$ para as importações do país $j$ no tempo $t ; I_{i}$ e $I F C_{j}$ representam os índices de facilitação de comércio construídos para os países $i$ em relação as importações e para os países $j$ em relação às exportações; $M s u l_{i j}$ é uma variável dummy que assume valor 1 para comércio intramercosul; $M U E_{i j}$ é uma dummy que assume valor 1 para comércio entre países do Mercosul e União Europeia; Mmundo $i j$ é uma dummy que assume valor 1 para comércio entre países do Mercosul e demais parceiros comerciais; $U E M_{i j}$ é uma dummy que assume valor 1 para comércio entre países da União

\footnotetext{
${ }^{1}$ Para uma descrição detalhada do modelo consultar Santos Silva e Tenreyro (2006)
} 
Europeia e do Mercosul; UEij é uma dummy que assume valor 1 para comércio intramercosul e $\varepsilon_{i j t}$ é o termo de erro aleatório.

A escolha da utilização das importações para medir o fluxo de comércio, ou seja, como variável independente, é usual na literatura empírica pelo fato de que os países fazem uma melhor coleta de dados sobre importações do que para as exportações (BALDWIN; TAGLIONI, 2006; SOUZA; BURNQUIST, 2012; ALMEIDA; GOMES; SILVA, 2014). Os dados sobre importação correspondem ao valor total das importações de acordo com a classificação por categorias do Sistema Harmonizado (SH02). A análise dos dados recai sobre o período 2010-2016, que corresponde à disponibilidade dos dados utilizados para a construção dos índices através da análise fatorial. Os países incluídos na amostra são os membros do Mercosul e os países membros da União Europeia, além dos seus principais parceiros comerciais, considerando o fluxo bilateral intrabloco, entre os países dos dois blocos e os demais parceiros. No total, a amostra possui 52 países $^{2}$. A descrição e fonte dos dados estão conforme a Tabela 2 .

Tabela 2- Variáveis utilizadas no modelo gravitacional

\begin{tabular}{|c|c|c|c|}
\hline Variável & $\begin{array}{c}\text { Sinal } \\
\text { esperado }\end{array}$ & Descrição & Fonte \\
\hline Importações & & Valor total das importações no ano $t$ & $\begin{array}{l}\text { COMTRADE (Nações } \\
\text { Unidas) }\end{array}$ \\
\hline $\begin{array}{l}\text { Produto Interno } \\
\text { Bruto (PIB) }\end{array}$ & + & Valor nominal em bilhões de dólares. & Banco Mundial \\
\hline Distância & - & Medida em Km & $\begin{array}{l}\text { Centre D'Estudes } \\
\text { Prospectives et } \\
\text { d'Informations } \\
\text { Internationales - CEPII }\end{array}$ \\
\hline $\begin{array}{l}\text { Tarifa sobre } \\
\text { importações }\end{array}$ & - & $\begin{array}{l}\text { Tarifa média aplicada sobre } \\
\text { importações }\end{array}$ & $\begin{array}{l}\text { World Integrated Trade } \\
\text { Solution (WITS) }\end{array}$ \\
\hline
\end{tabular}

\footnotetext{
${ }^{2}$ Países da amostra: África do Sul, Alemanha, Arábia Saudita, Argentina, Austrália, Áustria, Bélgica, Brasil, Bulgária, Canada, Chile, China, Chipre, Cingapura, Colômbia, Coreia do Sul, Croácia, Dinamarca, Eslováquia, Eslovênia, Espanha, Estónia, Estados Unidos, Finlândia, França, Grécia, Hong Kong, Hungria, Índia, Indonésia, Iran, Irlanda, Itália, Japão, Letônia, Lituânia, Luxemburgo, Malásia, Malta, México, Países Baixos, Paraguai, Polônia, Portugal, Reino Unido, República Tcheca, Roménia, Rússia, Suécia, Suíça, Uruguai, Venezuela
} 


\begin{tabular}{|c|c|c|c|}
\hline Índices de & & Indicam o nível de facilitação do & Elaboração própria a \\
\hline Facilitação do & + & comércio para importações e & partir dos dados do \\
\hline Comércio (ICF) & & exportações & Doing Bussines \\
\hline $\begin{array}{l}\text { Comércio Intra- } \\
\text { Mercosul }\end{array}$ & + & $\begin{array}{l}\text { Variável dummy para o comércio } \\
\text { entre membros do Mercosul }\end{array}$ & Elaboração própria \\
\hline $\begin{array}{l}\text { Comercio } \\
\text { Mercosul - } \\
\text { União Europeia }\end{array}$ & + & $\begin{array}{l}\text { Variável dummy para o comércio } \\
\text { entre países do Mercosul e União } \\
\text { Europeia }\end{array}$ & Elaboração própria \\
\hline $\begin{array}{l}\text { Comércio } \\
\text { Mercosul - } \\
\text { Mundo }\end{array}$ & + & $\begin{array}{l}\text { Variável dummy para o comércio } \\
\text { entre membros do Mercosul e } \\
\text { demais parceiros comerciais }\end{array}$ & Elaboração própria \\
\hline Comércio União & & Variável dummy para o comércio & \\
\hline $\begin{array}{l}\text { Europeia - } \\
\text { Mercosul }\end{array}$ & + & $\begin{array}{l}\text { entre países da União Europeia e } \\
\text { Mercosul }\end{array}$ & Elaboração própria \\
\hline $\begin{array}{l}\text { Comércio Intra } \\
\text { União Europeia }\end{array}$ & + & $\begin{array}{l}\text { Variável dummy para o comércio } \\
\text { entre membros da União Europeia }\end{array}$ & Elaboração própria \\
\hline
\end{tabular}

Fonte: Elaboração própria.

O teste de Hausman é utilizado para identificar se o modelo de dados em painel se adapta melhor aos efeitos fixos ou aleatórios. Sua aplicação busca verificar se o componente não observado $\alpha_{i j}$, no caso de efeitos fixos, se correlacionam com a matriz $X_{i j}$. Os efeitos fixos se mostram mais adequados se houver a correlação, e, caso isso não seja identificado, os efeitos aleatórios são os mais adequados. A hipótese nula, $\mathrm{H}_{0}$, indica que não há correlação entre o componente não observado e os regressores. O teste de Woodridge é utilizado para identificar se há autocorrelação entre o erro aleatório e as variáveis $X_{i j}$, onde a hipótese nula é de não existência de autocorrelação. Foram realizados também o teste de Wald para heteroscedasticidade na regressão com efeitos fixos, cuja hipótese nula implica que o modelo seja homoscedastico, e também o teste de Brusch Pagan e teste Chow (F) para identificar se os modelos de efeitos fixos e aleatórios se adaptam melhor que o modelo de regressão pooled. 


\section{ANÁLISE E DISCUSSÃO DOS RESULTADOS}

Nesta seção, estão os resultados obtidos através da estimação do método de análise fatorial para a construção dos índices de facilitação do comércio bilateral. Na primeira parte da seção, são apresentados os procedimentos realizados e os índices construídos a partir da análise fatorial. A segunda parte da seção apresenta os resultados referentes à estimação do modelo gravitacional.

\subsection{Resultado da Análise Fatorial e Indicadores}

Com a aplicação do método de análise fatorial, foi possível construir dois índices relativos aos procedimentos de realização de comércio bilateral. Os índices construídos foram o "Índice de facilitação de comércio para importações" e o "Índice de facilitação de comércio para exportações”. Eles sintetizam as variáveis selecionadas de procedimentos de comércio e podem indicar características das políticas comerciais dos países da amostra. As variáveis utilizadas foram padronizadas e, como elas indicam escalas de tempo e de custo, os sinais dos valores após a padronização foram alterados. Assim, quando o sinal é positivo, passa a ser negativo e, da mesma forma, caso o contrário. Esse procedimento faz com que os países que apresentam maiores custos e tempo para realização de procedimentos de comércio apresentem um índice menor de facilitação de comércio.

Os índices de importação se restringem aos países membros dos blocos do Mercosul e da União Europeia, que são os países nos quais o fluxo de comércio de importação será a variável dependente do modelo econométrico estimado na sequência. Porém os índices de exportação abrangem todos os países da amostra, já que dos parceiros comerciais são as exportações que são analisadas no modelo econométrico. O índice é representativo do período de análise, 2010-2016, e, como alguns países não apresentavam dados para alguns anos, foram utilizadas as médias das variáveis no período. Os índices foram definidos em uma escala em que seu valor varie entre 0 e 1 , e, para tanto, o valor mínimo da amostra é subtraído da observação e dividido pela diferença entre o valor máximo da amostra e o valor mínimo. Dessa forma, os valores mais próximos de 1 indicam maior facilitação do comércio e os que apresentam um índice mais próximo de 0 , o contrário.

\subsection{1 Índice de facilitação do comércio para importações}


O primeiro procedimento realizado para que seja possível prosseguir na utilização da análise fatorial foi verificar a existência de correlação entre as variáveis. A matriz de correlação possibilita que os fatores não conhecidos a princípio sejam relacionados com as variáveis padronizadas. As variáveis apresentaram correlação e positivamente em sua grande maioria, o que possibilita a aplicação do método de análise fatorial. O teste KMO é utilizado para verificar se os dados se ajustam adequadamente ao procedimento, e o resultado do teste vai de 0 a 1 e, ainda que não exista um valor consensual no qual o modelo esteja adequadamente ajustado, são consideradas faixas. O teste apresentou um valor de 0.712 , o que indica que o modelo está em uma faixa entre 0.7 e 0.8 e que tem boa adequação. A Tabela 3 apresenta os fatores encontrados com a aplicação da análise fatorial através da utilização de componentes principais.

Tabela 3- Fatores selecionados e porcentagem da variância

\begin{tabular}{ccccc}
\hline Fator & Variância & Diferença & Proporção & Acumulado \\
\hline Fator 1 & 5.94181 & 3.98329 & 0.4952 & 0.4952 \\
Fator 2 & 1.95852 & 0.39848 & 0.1632 & 0.6584 \\
Fator 3 & 1.56004 & & 0.13 & 0.7884 \\
\hline
\end{tabular}

LR test: independent vs. saturated: $\operatorname{chi} 2(66)=415.36$ Prob $>$ chi $2=0.0000$

Fonte: Resultados da pesquisa

Após a rotação dos fatores através do método Varimax, foram identificados três fatores e esses valores conjuntamente podem explicar 78,84\% da variação total das variáveis originais. $\mathrm{O}$ teste de esfericidade de Bartllet é apresentado abaixo da tabela e com o p-valor muito baixo indica que se rejeita a hipótese de que a matriz de correlação é estatisticamente igual à matriz identidade. A Tabela 4 apresenta as cargas fatorais e as comunalidade após a rotação pelo método Varimax e demonstra como cada carga fatorial se relaciona com as variáveis originais.

Tabela 4- Carga fatorial e comunalidade

\begin{tabular}{ccccc}
\hline Variável & Fator 1 & Fator 2 & Fator 3 & Comunalidade \\
\hline rp-npr & 0.3175 & 0.4668 & $\mathbf{0 . 5 0 6 1}$ & 0.4251 \\
Rpd & 0.1109 & -0.065 & $\mathbf{0 . 9 1 4 6}$ & 0.147 \\
Ndoc & 0.5285 & $\mathbf{0 . 6 4 0 4}$ & 0.1255 & 0.2948 \\
Custo & $\mathbf{0 . 9 6 5 7}$ & 0.0634 & 0.0921 & 0.0549
\end{tabular}




$\begin{array}{ccccc}\text { Tempo } & \mathbf{0 . 9 1 3 8} & 0.1148 & 0.1416 & 0.1318 \\ \text { Tdoc } & \mathbf{0 . 9 6 1 9} & 0.0069 & 0.0602 & 0.0711 \\ \text { tfront } & \mathbf{0 . 9 7 7 8} & 0.0444 & 0.0492 & 0.0395 \\ \text { Cdoc } & \mathbf{0 . 8 8 5 2} & 0.1721 & 0.1138 & 0.1739 \\ \text { cfront } & \mathbf{0 . 8 7 3 5} & 0.2888 & 0.0943 & 0.1447 \\ \text { c-npd } & -0.0344 & \mathbf{0 . 9 3 0 2} & -0.0605 & 0.1298 \\ \text { c-dur } & 0.0007 & \mathbf{0 . 5 0 8} & 0.4732 & 0.518 \\ \text { c-cust } & \mathbf{0 . 5 9 3 9} & -0.2656 & -0.4095 & 0.409\end{array}$

Fonte: Resultados da pesquisa

O Fator 1 está fortemente correlacionado com todas as variáveis correspondentes aos processos de comércio internacional que envolvem os procedimentos e custos alfandegários, que são "Custo para importar”, “Tempo para importar”, “Tempo para importar: Conformidade com a documentação", "Tempo para importar: Conformidade com obrigações na fronteira", "Custo para importar: Conformidade com a documentação" , "Custo para importar: Conformidade com obrigações na fronteira" e "Execução de contratos - Custo". Esse fator é relacionado, então, com os "Custos e elementos de fronteira". O segundo fator está relacionado com as variáveis "Número de documentos para importar", "Execução de contratos - Número de procedimentos" e "Execução de contratos - Duração", que envolvem os procedimentos burocráticos dentro dos países e seriam os elementos dentro da fronteira, então podem ser denominados como "estrutura burocrática". O terceiro fator se relaciona com as variáveis "Registro de propriedades - Número de procedimentos" e "Registro de propriedades - Duração" e pode ser denominado com simplesmente "registro de propriedade".

Para a construção dos índices, são obtidos os escores dos fatores encontrados para cada elemento da amostra, que são um valor de cada um dos três fatores utilizados no modelo para cada país da amostra. Cada escore é multiplicado pela razão entre a variância explicada de cada fator e a variância acumulada dos três fatores, apresentados na Tabela 4. Após esse procedimento, o índice é dado pela soma dos escores dos três fatores "custos e elementos de fronteira", "estrutura burocrática" e "registro de propriedade". O índice sintetiza todos esses elementos e busca identificar a prática de facilitação de comércio nos países da amostra e possibilita ranquear os países de acordo com essas práticas como na figura a seguir. 


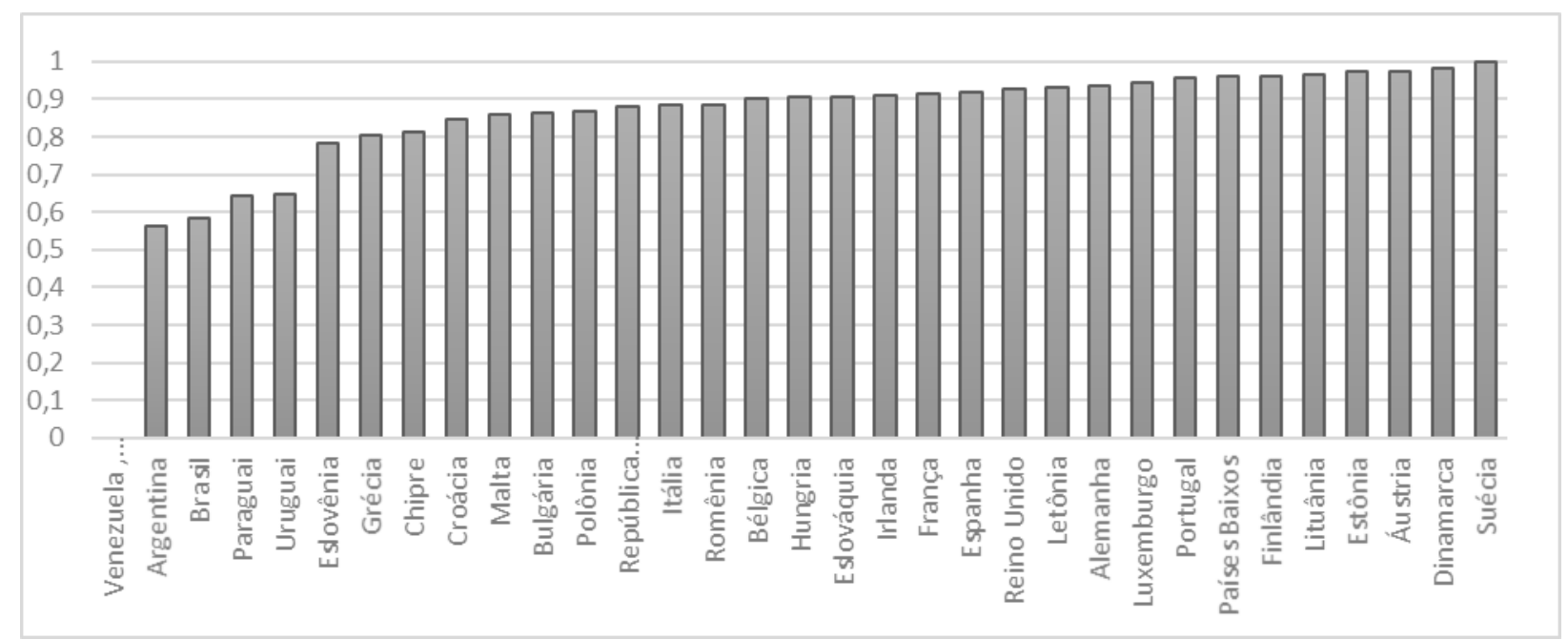

Figura 1- Ranking do Índice de facilitação do comércio para importações

Fonte: Resultados da pesquisa

Os países membros do Mercosul apresentaram os piores resultados, encontrando-se no primeiro quartil da amostra conforme o ordenamento crescente dos índices. A Venezuela apresentou o menor índice de facilitação de comércio para importações da amostra, cujo índice fica em zero devido ao procedimento de mudança de escala do índice, da mesma forma a Suécia, que apresenta o melhor resultado, corresponde ao valor igual a um. Destacam-se os países nórdicos e dos países bálticos entre os com maiores índices. $\mathrm{O}$ índice médio para o Mercosul foi de 0.49 , incluindo a Venezuela, e de 0.61 , já que este país apresentou um resultado muito baixo até mesmo em relação aos demais países do bloco. Essa média está consideravelmente abaixo dos índices dos países da União Europeia. A Eslovênia, que é o país com o menor índice, apresentou um resultado de 0.78 e a média para o bloco é de 0.91 .

Ambos os blocos são constituídos por economias bastante distintas, sendo difícil traçar um panorama da facilitação de comércio para importações para cada bloco. No entanto o Mercosul apresentou resultados mais uniformes entre seus países com exceção da Venezuela e de forma geral os países da União Europeia apresentam uma estrutura burocrática e de custos que propiciam maior facilitação de comércio para as importações. Geralmente os índices de facilitação para as importações se mostram piores do que para as exportações, pois algumas restrições às importações podem indicar práticas de protecionismo. Esses resultados estão em consonância com os resultados encontrados em Souza e Burniquist (2011, 2012), onde os países da América do Sul apresentavam baixos índices de eficiência de procedimentos de facilitação de comércio, assim como os índices relacionados à importação apresentaram menor eficiência. 


\subsection{2 Índice de facilitação do comércio para importações}

Da mesma forma que para o procedimento de análise fatorial para os índices relativos à importação, a primeira etapa consiste em verificar a existência de correlação entre as variáveis relacionadas à exportação. Para esta estimação, não são utilizadas as variáveis "Registro de propriedades - Número de procedimentos" e "Registro de propriedades Duração". Novamente todas as variáveis possuem correlação e quase em sua totalidade positiva. Para essa estimação, o teste KMO apresentou o valor de 0.78 , um resultado melhor do que para a análise anterior, mas ainda na faixa de adequação classificada como boa. Novamente foram encontrados três fatores após a rotação dos fatores através do método Varimax como pode ser visto na Tabela 6.

Tabela 6- Fatores selecionados e porcentagem da variância

\begin{tabular}{ccccc}
\hline Fator & Variância & Diferença & Proporção & Acumulado \\
\hline Fator 1 & 4.44586 & 2.66596 & 0.4446 & 0.4446 \\
Fator 2 & 1.7799 & 0.15138 & 0.178 & 0.6226 \\
Fator 3 & 1.62852 & & 0.1629 & 0.7854 \\
\hline
\end{tabular}

LR test: independent vs. saturated: $\operatorname{chi} 2(45)=391.21$ Prob $>$ chi $2=0.000$

Fonte: Resultados da pesquisa

Esses podem explicar $78,84 \%$ da variação total das variáveis originais. O teste de esfericidade de Bartllet novamente apresenta um p-valor muito próximo a zero, logo rejeita-se a hipótese de que a matriz de correlação seja estatisticamente igual à matriz identidade. A Tabela 8 apresenta as cargas fatorais e as comunalidades.

Tabela 7- Carga fatorial e comunalidade

\begin{tabular}{ccccc}
\hline Variável & Fator 1 & Fator 2 & Fator 3 & Comunalidade \\
\hline ndoc & $\mathbf{0 . 6 8 0 3}$ & 0.0983 & 0.4059 & 0.3628 \\
custo & $\mathbf{0 . 7 1 2 2}$ & 0.5547 & 0.0267 & 0.1843 \\
tempo & $\mathbf{0 . 6 6 2 2}$ & 0.5038 & 0.3468 & 0.1874 \\
tdoc & $\mathbf{0 . 7 8 7 3}$ & 0.5007 & -0.0049 & 0.1294 \\
tfront & $\mathbf{0 . 9 0 1 6}$ & 0.2838 & 0.1248 & 0.091 \\
cdoc & $\mathbf{0 . 8 8 8}$ & -0.0025 & -0.0147 & 0.2113 \\
cfront & $\mathbf{0 . 8 8 7 9}$ & -0.0544 & 0.0019 & 0.2086 \\
c-npd & 0.144 & -0.2225 & $\mathbf{0 . 8 4 2 6}$ & 0.2197
\end{tabular}



c-dur
$-0.0334$
0.2543
0.7855
0.3172
c-cust
0.0753
$\mathbf{0 . 8 7 2}$
0.0038
0.234

Fonte: Resultados da pesquisa

Para as variáveis referentes à exportações, o Fator 1 está fortemente correlacionado com todas as variáveis que correspondem aos procedimentos e custos alfandegários, as quais são "Custo para exportar”, “Tempo para exportar”, “Tempo para exportar: Conformidade com a documentação", "Tempo para exportar: Conformidade com obrigações na fronteira", "Custo para exportar: Conformidade com a documentação", "Custo para exportar: Conformidade com obrigações na fronteira" e "Número de documentos para exportar". Esse fator é relacionado estritamente com os "elementos de fronteira". O segundo fator está relacionado com as variáveis, "Execução de contratos - Número de procedimentos" e "Execução de contratos - Duração", que novamente podem ser denominados como "estrutura burocrática". O terceiro fator se relaciona com as variáveis "Execução de contratos - custos" e pode ser denominado simplesmente como "custo de contratos". Os índices foram construídos utilizando o mesmo procedimento utilizado para os índices de importação, e os resultados são apresentados a seguir.

Figura 2. Ranking do Índice de facilitação do comércio para exportações

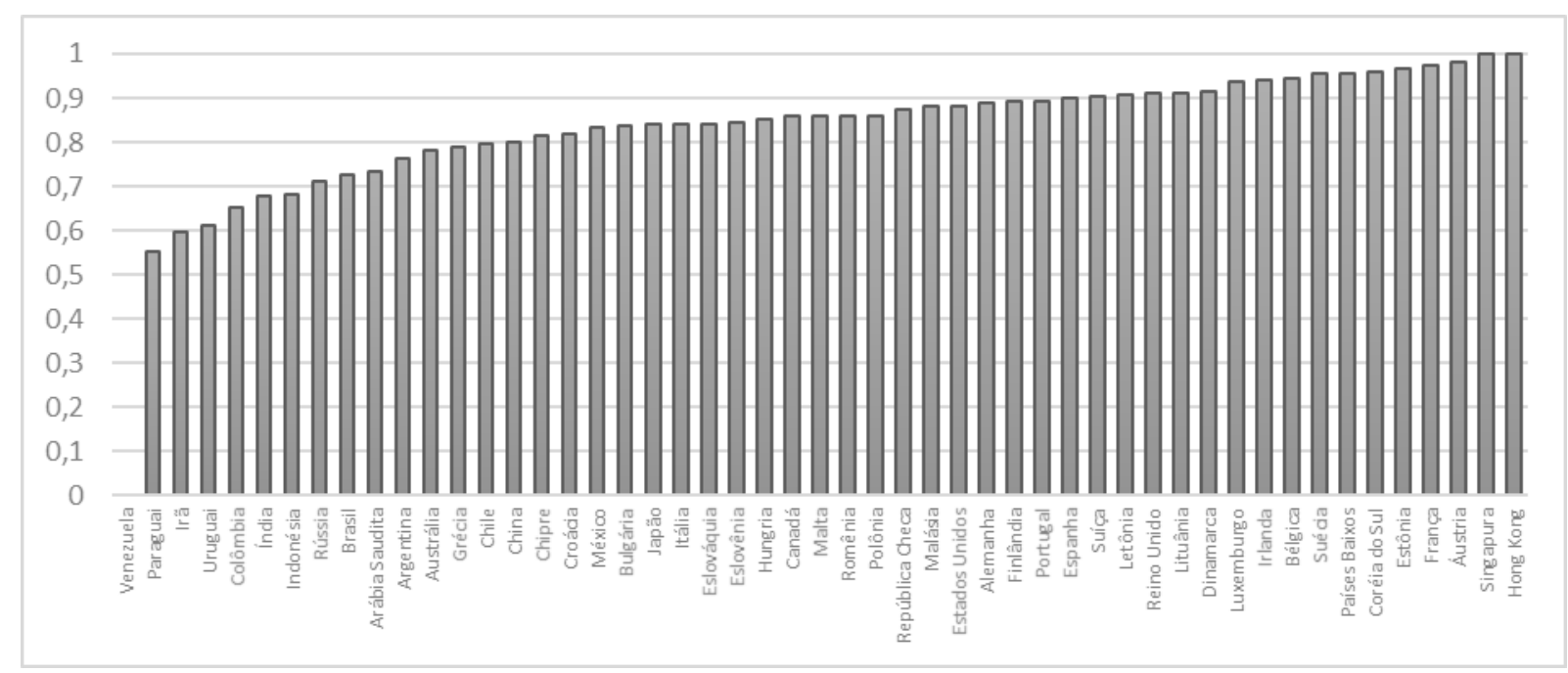

Fonte: Resultados da pesquisa

Essas partes da análise envolvem uma amostra maior de países, pois englobam os demais parceiros comerciais, além dos países do Mercosul e União europeia. Os resultados são semelhantes à estimação para as importações, e os países do Mercosul aparecem entre os 
países com índice mais baixo e novamente a Venezuela apresenta o pior resultado da amostra. O Brasil apresenta um índice melhor e estão à frente os demais países do Mercosul, com exceção da Argentina e dos países dos BRIC'S, por exemplo, o que pode indicar maior protecionismo, já que existe uma facilitação melhor para as exportações. Os países escandinavos e a Áustria também mantêm um patamar próximo à estimação anterior, e a França apresenta um índice maior, ficando entre os maiores da amostra. Hong Kong é o país com o maior índice da amostra. O Mercosul apresentou uma média maior para esse índice, sendo 0.53 com a Venezuela e 0.66 sem este país. A média geral da amostra é 0.82 , e, mesmo com um índice maior, o nível de facilitação de comércio para o Mercosul ainda fica consideravelmente abaixo, até para as exportações.

\subsection{Resultados da estimativa em dados em painel do modelo gravitacional}

Nesta seção, são apresentados e discutidos os resultados referentes à estimação do modelo gravitacional em relação ao impacto dos índices criados sobre as relações de comércio internacional dos países membros do Bloco do Mercosul comparativamente às relações apresentadas pelos membros da União Europeia. São apresentados os resultados das regressões em dados em painel Pooled, Efeitos Fixos ${ }^{3}$, Efeitos Aleatórios e PPML com efeitos fixos.

\subsubsection{Estimativas do modelo gravitacional e testes}

As Tabelas 8 e 9 apresentam, respectivamente, os testes de adequação do modelo em dados em painel, heteroscedasticidade e autocorrelação e os coeficientes estimados do modelo. De modo geral, os coeficientes estimados apresentaram o sinal esperado pela teoria, mas, em alguns dos modelos, com baixa magnitude ou pouca significância estatística. Os resultados do teste $\mathrm{F}$ (Chow) referente ao modelo de efeitos fixos e de Brusch Pagan para efeitos aleatórios com o p-valor muito próximo de zero demonstram que esses modelos obtêm resultados mais eficientes do que o modelo pooled. O resultado do teste de Hausman leva à rejeição da hipótese nula de que não existe correlação entre o termo $z_{i}$, não observado com as

\footnotetext{
${ }^{3}$ Devido ao fato de o modelo possuir variáveis continuas o modelo de efeitos fixos não consegue captar o efeito destas, para que seja possível realizar a análise dessas variáveis através do modelo de efeitos fixos foi necessário utilizar um método denominado Vetor de decomposição de efeitos fixos que possibilita obter os coeficientes das variáveis com valores contínuos, esse modelo é proposto em Plümper e Troeger (2004).
} 
variáveis independentes $x_{i t}$, nesse caso, a hipótese de que as heterogeneidades dos países não afetem o comércio bilateral. Logo, o modelo de efeitos fixos apresenta as estimativas mais eficientes, como indicado na literatura sobre o modelo gravitacional em Anderson; Van Wincoop (2003); Santos Silva e Tenreyro, (2006); Baldwin e Taglioni (2006).

Tabela 8- Testes de ajuste do modelo

\begin{tabular}{lll}
\hline Testes & $\mathrm{F} / \mathrm{chi} 2$ & $\mathrm{p}$-valor \\
\hline Chow & $\mathrm{F}(970,5233)=45.05$ & 0.0000 \\
Hausman & $\operatorname{chi} 2(9)=583.19$ & 0.0000 \\
Wald & $\operatorname{chi} 2(971)=9.5 \mathrm{e}+31$ & 0.0000 \\
Brusch Pagan & chibar2(01) $=10443.49$ & 0.0000 \\
Wooldridge & $\mathrm{F}(1,937)=16.584$ & 0.0001 \\
\hline
\end{tabular}

Fonte: Elaboração própria a partir dos resultados da pesquisa.

O teste de Wald para efeitos fixos indica a rejeição da hipótese nula de homoscedasticidade neste modelo, e o resultado do teste de Woodridge para os modelos de efeitos fixos e de efeitos aleatórios leva à rejeição de hipótese nula de não existência de autocorrelação. Desta forma, os resultados apresentados para os coeficientes dos modelos de efeitos fixos, aleatórios e PPML são estimações realizadas com a utilização de erros robustos para a correção dos problemas de heteroscedasticidade e autocorrelação.

Tabela 9- Resultados das estimativas do modelo gravitacional

\begin{tabular}{ccccc}
\hline \multirow{2}{*}{ Variável } & \multicolumn{3}{c}{ Modelo } \\
\cline { 2 - 5 } & $\begin{array}{c}\text { Regressão } \\
\text { Pooled }\end{array}$ & Efeitos & PPML - EF & Efeitos \\
& $1.100^{* * *}$ & $1.066^{* * *}$ & $0.480 * * *$ & $1.089^{* * *}$ \\
\hline Lpibi & $(0.012)$ & $(0.005)$ & $(0.097)$ & $(0.033)$ \\
& $0.956^{* * *}$ & $0.026^{* * *}$ & $0.008^{* *}$ & $0.443 * * *$ \\
Lpibj & $(0.014)$ & $(0.007)$ & $(0.009)$ & $(0.044)$ \\
& $-0.056^{* * *}$ & $-0.068^{* * *}$ & $-0.005^{*}$ & -0.022 \\
Ltarifa & $(0.015)$ & $(0.007)$ & $(0.002)$ & $(0.032)$ \\
& $0.417 * * *$ & $0.425^{* * *}$ & - & $0.410 * * *$ \\
Lindicem & $(0.065)$ & $(0.027)$ & - & $(0.146)$
\end{tabular}




\begin{tabular}{ccccc} 
Lindicex & $1.842 * * *$ & $2.014 * * *$ & - & $1.781 * * *$ \\
Ldist & $(0.068)$ & $(0.053)$ & - & $(0.229)$ \\
& $-0.704 * * *$ & $-0.758 * * *$ & - & $-0.789 * * *$ \\
Intramercosul & $(0.032)$ & $(0.009)$ & - & $(0.085)$ \\
Mercosulue & $2.864 * * *$ & $1.382^{* * *}$ & - & $1.883 * * *$ \\
& $(0.172)$ & $(0.083)$ & - & $(0.419)$ \\
Mercomundo & -0.115 & $-1.550 * * *$ & - & $-0.964 * * *$ \\
& $(0.083)$ & $(0.034)$ & - & $(0.221)$ \\
Uemercosul & $0.431 * * *$ & $0.487 * * *$ & - & $0.450 * * *$ \\
& $(0.086)$ & $(0.034)$ & - & $-0.676 * * *$ \\
Intraue & 0.068 & $-1.292 * * *$ & - & $(0.205)$ \\
& $(0.071)$ & $(0.032)$ & - & $-1.069 * * *$ \\
Constante & $0.324 * *$ & $-1.735 * * *$ & - & $(0.293)$ \\
& $(0.146)$ & $(0.035)$ & - & $-13.935 * * *$ \\
R2 & $-29.140 * * *$ & $-1.985 * * *$ & - & $(1.750)$ \\
$\mathrm{N}$ & $(0.589)$ & $(0.249)$ & - & 0.6781 \\
& 0.7318 & 0.9609 & - & 6213 \\
\hline & 6213 & 6213 & 6210 & \\
\hline
\end{tabular}

*** significância à 1; ** significância à 5\%; *significância à 10\%

Fonte: Elaboração própria a partir dos resultados da pesquisa

Em relação à estimação do modelo de efeitos fixos, que é o que melhor se adequou ao modelo proposto, o coeficiente para o PIB do país importador apresentou o sinal positivo como o esperado e foi bastante significativo estatisticamente, com o valor próximo à unidade como verificado em Santos Silva e Tenreyro, (2006) e Souza e Burnquist (2012). Como os dois lados da equação estando em logaritmos, os resultados representam elasticidades, o que significa, para o caso do PIB do país importador, um aumento de $10 \%$ na renda nacional. Mantendo tudo mais constante, representaria um acréscimo aproximado de 10, 66\% no fluxo de importações. No entanto, para essa estimação, o PIB do país exportador apresentou alta significância estatística, mas um coeficiente com baixa magnitude, muito abaixo do coeficiente do PIB do país importador, ao contrário do que indica esta mesma literatura. Apenas na estimação em pooled apresentou um coeficiente para o PIB do país exportador próximo ao coeficiente do PIB do país importador. 
O coeficiente da variável tarifa média aplicada também apresentou o resultado esperado para efeitos fixos, sendo negativo e também foi significativo estatisticamente, mas com uma magnitude de impacto mais baixa do que o encontrado em Souza e Burnquist (2012), Sant'Anna e Souza (2014), mas próximo ao encontrado em Paula, Silva, Almeida (2012). Essa diferença de resultados pode ser resultado da diferença de agregação dos dados, no caso dos dois primeiros trabalhos, os valores das taxas são desagregados por produtos, enquanto, neste último e no presente trabalho, são as taxas médias aplicadas sobre as categorias de produtos como um todo sobre as importações. Isso pode representar uma redução na capacidade de explicação dessas variáveis, já que as taxas sobre importação podem variar bastante de acordo com o produto. Essa variável não foi significativa apenas na estimação com efeitos aleatórios.

A variável distância apresentou o sinal negativo como esperado pela teoria e foi significativa estatisticamente e com uma magnitude muito próxima em todos os modelos. Os coeficientes para os índices, que são o foco da análise, apresentaram sinal positivo como esperado e foram significativos estatisticamente em todas as estimações, tendo o maior coeficiente no modelo de efeitos fixos. Os índices representam o grau de eficiência para a realização de comércio bilateral, tento no aspecto alfandegário como de procedimentos internos ao país, o que implica que a melhoria da eficiência desses procedimentos por essa estimativa representa um impacto maior no fluxo comércio do que representaria uma redução das tarifas aplicadas. Resultados semelhantes são encontrados em Souza e Burnquist (2011, 2012, onde a melhoria dos índices dos países exportadores representa um impacto maior sobre o aumento do fluxo de comércio do país importador e, em Wilson, Mann e Otsuki (2003), analisando os países da APEC e Sant'Anna e Souza (2014), analisando o Brasil especificamente, mas para estes estudos, convergindo com o resultado encontrado neste por esta estimativa, é a melhoria na realização dos procedimentos internos que resultaria em maior impacto sobre fluxo de comércio.

Os resultados para o modelo PPML apresentaram os sinais esperados pela teoria, mas com baixa significância estatística, com exceção do PIB do país importador. Tinha-se a perspectiva de uma melhor adequação do modelo como indicado em Santos Silva e Tenreyro, (2006), Shepherd e Wilson (2008), já que o modelo mostra bons resultados quando a variável dependente apresenta muito número de valores igual a zero. Outro problema encontrado é o fato de o modelo ser estimado utilizando efeitos fixos e as variáveis contínuas no tempo não são captadas. Nesta estimação, não foi possível aplicar o método utilizado no modelo de 
efeitos fixos tradicionais para o tratamento dessas variáveis. Os coeficientes para o PIB do país importador e exportador foram positivos, mas o segundo não foi significativo estatisticamente. O coeficiente para as tarifas obteve sinal negativo e é significativo estatisticamente. Mas nenhuma dessas variáveis representaria impactos significantes sobre o fluxo de importação em caso de mudança para essa estimativa. Por exemplo, um aumento de $10 \%$ do PIB do país importador ou exportador ou da taxa média aplicada pelo país importador não representaria uma mudança de sequer $1 \%$ sobre o volume de importações.

Os coeficientes para as variáveis dummies que representam o comércio intrabloco, entre os blocos e com os demais parceiros comerciais, apresentaram resultados distintos. Os coeficientes que representam o comércio entre os membros do Mercosul apresentaram sinal positivo, são significativos estatisticamente e com a maior magnitude em relação às demais variáveis binárias. Isso indica que os países do Mercosul têm, entre seus principais parceiros comerciais, os demais países do bloco, o que é um resultado esperado devido ao fato de todos os países pertencerem ao mesmo continente e participarem de um APC's. Mas também pode representar uma forma de desvio de comércio, como identificado em Azevedo (2004) e Reis e Azevedo (2008), já que os coeficientes da variáveis dummy para a relação de comércio entre Mercosul e União Europeia e com os demais parceiros comerciais apresentam uma magnitude bem menor ou negativa.

No caso da relação de comércio Mercosul-União Europeia, os coeficientes apresentaram sinais negativos e significativos estatisticamente para efeitos fixos, para a relação União Europeia-Mercosul, mesmo sendo o bloco europeu um de seus principais parceiros comerciais, ao contrário do que ocorre para o comércio com os demais parceiros comerciais, onde o coeficiente é positivo e significativo, o que pode indicar um redirecionamento do comércio dos países do Mercosul em direção a outros mercados no período analisado. Para a variável dummy de comércio entre os países membros da União Europeia, os coeficientes apresentaram sinais negativos, menos para a estimação por pooled, cujo sinal é positivo como esperado e significativo estatisticamente a 5\%. No caso do coeficiente para efeitos aleatórios, o sinal é negativo e estatisticamente significativo ao nível de $1 \%$. Isso pode indicar um direcionamento maior das exportações do bloco para outros países não membros.

De forma geral, pode-se destacar que os índices de facilitação do comércio possuem um efeito significativo sobre as relações de comércio e melhorias de eficiência de procedimentos burocráticos e a redução dos custos desses procedimentos representariam um 
ganho de comércio em relação ao volume de importações, mais significativo que até mesmo reduções nas tarifas aplicadas. Quanto às relações de comércio dos blocos, o fluxo intrabloco tem um impacto maior para o Mercosul do que para a União Europeia, e o impacto da relação entre os dois blocos não foi significativo. Mesmo com os países do bloco europeu apresentando bons índices de facilitação de comércio, as relações de comércio intrabloco não têm um peso tão grande quanto para o caso do Mercosul e também sobre a relação entre os dois blocos, o que parece indicar que, mesmo com os países do Mercosul apresentando alguns dos piores índices de facilitação de comércio, as suas relações comerciais se direcionam para o comércio entre os membros do bloco.

\section{CONCLUSÃO}

A proposta central do artigo foi alcançada em grande medida com a utilização do método de análise fatorial para a criação dos índices de facilitação do comércio e aplicação do modelo gravitacional para medir o impacto desses índices e demais fatores sobre os fluxos de comércio dos países dos blocos do Mercosul e União Europeia. Os resultados da análise fatorial foram satisfatórios e possibilitaram a condensação de diversas variáveis que indicam a eficiência dos procedimentos e custos para a realização do comércio internacional em dois índices que indicam esse grau de eficiência para as importações e exportações. Com os índices obtidos, foi possível observar que os países do Mercosul estão entre os com piores índices de facilitação de comércio, principalmente no que se refere às importações, o que pode representar a adoção de políticas protecionistas por estes países.

Os resultados do modelo gravitacional corroboram o impacto positivo da melhoria desses índices sobre o fluxo de comércio dos países; melhorias nos procedimentos alfandegários e processos burocráticos internos dos países favorecem o comércio internacional, e o modelo estimado sugere que teriam um impacto maior que reduções nas tarifas aplicadas. Também foi possível perceber que o comércio realizado entre os países membros do Mercosul tem um peso significativo para os fluxos comerciais desses países, o que pode implicar um desvio de comércio em relação aos demais países como os da própria União Europeia, na qual as relações comerciais entre esses dois blocos não se mostraram significativas no período em análise.

No entanto o modelo possui algumas limitações. A indisponibilidade de dados sobre a eficiência dos procedimentos de comércio internacional limitou a criação de índices para 
todos os anos da análise, sendo possível apenas a criação de um índice que correspondesse a todo período. No entanto, mesmo com esta limitação, os índices apresentaram os coeficientes esperados e foram significativos. Outro problema encontrado foi na estimação do modelo PPML, amplamente utilizado em estudos sobre o tema, já que possui uma boa adequação a estes tipos de dados e que, neste caso, não apresentou resultados consistentes. Para trabalhos futuros, fica a possibilidade de expandir as fontes de dados e inserir outras variáveis que correspondam à facilitação do comércio que possam abranger diversos anos, assim como realizar essa estimativa com relação a outros blocos econômicos ou parceiro comerciais.

De modo geral, foi possível traçar um panorama de como está estabelecido o nível de eficiência dos aspectos relacionados à facilitação do comércio para os países dos dois blocos, destacando os ganhos de comércio provenientes das melhorias desses procedimentos e a necessidade que os países do Mercosul apresentam em obter essas melhorias para que se possibilite um melhor desempenho de comércio e até um maior alcance a outros mercados.

\section{REFERÊNCIAS}

ALMEIDA, F. M.; GOMES, M. F. M.; SILVA, O. M. Notificações aos acordos TBT e SPS: diferentes objetivos e resultados sobre o comércio internacional de agroalimentos. Revista de Economia e Sociologia Rural, v. 52, n. 1, p. 157-176, 2014.

ANDERSON, J. E.; VAN WINCOOP, Eric. Gravity with gravitas: a solution to the border puzzle. American economic review, v. 93, n. 1, p. 170-192, 2003.

AZEVEDO, A. F. Z. O efeito do Mercosul sobre o comércio: uma análise com o modelo gravitacional. Pesquisa e planejamento econômico (PPE), v.34, n.2, 2004.

BANCO MUNDIAL. World development indicators online. Disponível em: < http://datatopics.worldbank.org/world-development-indicators/>. Acesso em: 19 Set. 2018.

BALDWIN, R.; TAGLIONI, D. Gravity for dummies and dummies for gravity equations. National Bureau of Economic Research, 2006.

BAUMANN, Renato. O Mercosul aos vinte anos: uma avaliação econômica. Texto para Discussão, Instituto de Pesquisa Econômica Aplicada (IPEA), Brasília, 2011.

CENTRE D'ESTUDES PROSPECTIVES ET D'INFORMATIONS INTERNATIONALES CEPII. Disponível em: 
<http://www.cepii.fr/CEPII/fr/recherche/programmes_scientifiques.asp>. Acesso em: 18 Set. 2018.

COMMODITY TRADE STATISTICS-COMTRADE. United Nations commodity trade statistics database. Disponível em: 〈https://comtrade.un.org/>. Acesso em: 18 Set. 2018.

DOING BUSINESS. The World Bank. Disponível em: $<\mathrm{http}: / / \mathrm{www}$.doingbusiness.org/en/data>. Acesso em: 10 Set. 2018.

GRÄF, C. O.; AZEVEDO, A. F. Z. Comércio bilateral entre os países membros do mercosul: uma visão do bloco através do modelo gravitacional. Economia Aplicada, v. 17, n. 1, p. 135-158, 2013.

GREENE, W. H. Econometric analysis, 5th. Ed.. Upper Saddle River, NJ, p. 89-140, 2002.

MERCOSUL. Tratado para la constitucion de um mercado comum. Assunção, Paraguai, 1991.

MINGOTI, S. A. Análise de dados através de métodos de estatística multivariada: uma abordagem aplicada. Belo Horizonte: UFMG, 2005.

PAULA, J. S.; SILVA, O. M.; ALMEIDA, F. M. Evidências empíricas de indicadores de competitividade sobre os fluxos comerciais internacionais. Encontro Nacional de Economia, v. 40, 2012.

PEREIRA, L. C. V. A "nova onda de regionalismo": uma reflexão sobre a agenda brasileira. Mural Internacional, v. 4, n. 1, p. 2-7, 2013.

PLÜMPER, T.; TROEGER, V. E. The estimation of time-invariant variables in panel analyses with unit fixed effects. 2004.

REIS, M.; AZEVEDO, A. F. Z. O impacto da criação do Mercosul no fluxo de comércio bilateral: uma abordagem com o modelo gravitacional. In: Anais do XXXVI Encontro Nacional de Economia. ANPEC-Associação Nacional dos Centros de Pós-graduação em Economia, 2008

SADIKOV, A.M. Border and behind-the-border trade barriers and country exports. Working Paper-07/292 Washington, 2007.

SANT'ANNA, V. P.; SOUZA, M. J. P. Uma análise do impacto da facilitação de comércio sobre as exportações brasileiras. Anais do XLI Encontro Nacional de Economia, n. 123, 2014.

SHEPHERD, B.; WILSON, J. S. Trade facilitation in ASEAN member countries: Measuring progress and assessing priorities. The World Bank, 2008. 
SILVA, J.M.C.S.; TENREYRO, S. The log of gravity. The Review of Economics and statistics, v. 88, n. 4, p. 641-658, 2006.

SOUZA, M. J. P.; BURNQUIST, H. L. Impactos da facilitação de comércio: evidências do modelo gravitacional. Revista de Economia e Sociologia Rural, v. 49, n. 4, p. 909-940, 2011.

SOUZA, M. J. P.; FARIA, R. N.; SANT’ANNA, V. P.. Indicadores de facilitação de comércio: o caso do Brasil e seus parceiros comerciais. Revista de Economia e Relações Internacionais, São Paulo, Vol. 10/n. 20, p. 124 - 141 , 2012.

VALLE, V. M. V." O peso das relações inter-regionais com a União Europeia em relação a outras alternativas de política externa do Mercosul. Revista Brasileira de Política Internacional, v. 1, p. 95-128, 2005.

WILSON, J.S.; MANN, C.L.; OTSUKI, T. Trade facilitation and economic development: measuring the impact. Working Paper, 2988, 2003.

WORLD TRADE ORGANIZATION (WTO). World Trade Report 2015, Speeding up trade: benefits and challenges of implementing the WTO Trade Facilitation Agreement. World Trade Organization, 2015.

WORLD INTEGRATED TRADE SOLUTION (WITS). The World Bank. Disponível em: <https://wits.worldbank.org/>. Acesso em: 29 Set. 2018. 